\section{Brain injury in extracorporeal cardiopulmonary resuscitation: translational to clinical research}

\author{
Christopher Wilcox, DO, MS ${ }^{1,2}$; Chun Woo Choi, MD; \\ Sung-Min Cho, DO, $\mathrm{MHS}^{3}$
}

'Department of Neurosciences, Mercy Hospital of Buffalo, Buffalo, NY, USA

${ }^{2}$ Division of Cardiac Surgery, Department of Surgery, Johns Hopkins University School of

Medicine, Baltimore, MD, USA

${ }^{3}$ Division of Neuroscience Critical Care, Departments of Neurology, Neurosurgery, Anesthesiology, and Critical Care Medicine, Johns Hopkins University School of Medicine, Baltimore, MD, USA \\ Care \\ Received: June 10, 2021 \\ Accepted: June 29, 2021 \\ Corresponding Author: \\ Sung-Min Cho, DO, MHS \\ Division of Neuroscience Critical Care, \\ Department of Anesthesiology and \\ Critical Care Medicine, Johns Hopkins \\ Medical Institutions, 600 N. Wolfe \\ Street, Phipps 455, Baltimore, MD \\ 21287, USA \\ Tel: +1-410-955-2109 \\ Fax: +1-410-614-7903 \\ E-mail: csungmi1@jhmi.edu}

The addition of extracorporeal membrane oxygenation (ECMO) to conventional cardiopulmonary resuscitation (CPR), termed extracorporeal cardiopulmonary resuscitation (ECPR), has significantly improved survival in selected patient populations. Despite this advancement, significant neurological impairment persists in approximately half of survivors. ECPR represents a potential advancement for patients who experience refractory cardiac arrest (CA) due to a reversible etiology and do not regain spontaneous circulation. Important risk factors for acute brain injury (ABI) in ECPR include lack of perfusion, reperfusion, and altered cerebral autoregulation. The initial hypoxic-ischemic injury caused by no-flow and low-flow states after CA and during CPR is compounded by reperfusion, hyperoxia during ECMO support, and nonpulsatile blood flow. Additionally, ECPR patients are at risk for Harlequin syndrome with peripheral cannulation, which can lead to preferential perfusion of cerebral vessels with deoxygenated blood. Lastly, the oxygenator membrane is prothrombotic and requires systemic anticoagulation. The two competing phenomena result in thrombus formation, hemolysis, and thrombocytopenia, increasing the risk of ischemic and hemorrhagic ABI. In addition to clinical studies, we assessed available ECPR animal models to identify the mechanisms underlying $A B I$ at the cellular level. Standardized multimodal neurological monitoring may facilitate early detection of and intervention for ABI. With the increasing use of ECPR, it is critical to understand the pathophysiology of $A B I$, its prevention, and the management strategies for improving the outcomes of ECPR. Translational and clinical research focusing on acute $\mathrm{ABI}$ immediately after ECMO cannulation and its short- and long-term neurological outcomes are warranted.

Keywords: Extracorporeal membrane oxygenation; Acute brain injuries; Extracorporeal cardiopulmonary resuscitation

\section{INTRODUCTION}

The use of extracorporeal membrane oxygenation (ECMO) to treat patients with cardiac arrest (CA) was first described in 1957 when several patients with CA refractory to conventional cardio- pulmonary resuscitation (CCPR) including open cardiac massage were placed on cardiopulmonary bypass (CPB), allowing time for an attempt at definitive management [1]. A percutaneous system for ECMO cannulation initiated at the bedside was successfully implanted in five patients in 1983 by Phillips et al. [2]. Percutane-

(C) 2021 The Korean Neurocritical Care Society

This is an Open Access article distributed under the terms of the Creative Commons Attribution Non-Commercial License (http://creativecommons.org/licenses/by-nc/4.0/) which permits unrestricted noncommercial use, distribution, and reproduction in any medium, provided the original work is properly cited. 
ous ECMO was successfully applied to CA patients refractory to CCPR, which was termed extracorporeal cardiopulmonary resuscitation (ECPR), in 1991 when a specialized team achieved the 6-month survival of $64 \%$ of adult patients $(n=11)$ who had refractory CA close to a cardiac operating room [3]. A similar survival pattern was reported for children in 1992 when 11 patients aged 8-22 months were treated with ECMO for CA refractory to CCPR [4].

With the development of more portable ECMO devices and percutaneous implantation, ECPR has become possible in medical intensive care units and emergency rooms, expanding its potential use in patients with out-of-hospital cardiac arrest (OHCA) $[5,6]$. Multiple animal models have demonstrated improved survival and end-organ protection with ECPR, compared with CCPR, after CA [7-9]

Since the mid-2000s, the number of ECMO-capable centers participating in the Extracorporeal Life Support Organization (ELSO) has tripled, increasing the feasibility of ECPR [10-12]. Two meta-analyses of observational studies comparing ECPR and CCPR for patients with CA occurring in and outside of the hospital demonstrated an improvement in both survival and neurologic outcomes with ECPR. Both analyses showed improved survival among patients with in-hospital cardiac arrest (IHCA) on discharge and at 1-year follow-up. Patients with OHCA showed no difference in survival or neurologic outcomes on discharge; however, after 3-6 months, improvements in survival and neurologic outcomes were observed $[13,14]$. ECPR continues to be an active area of innovation; several clinical trials of emergency medical response teams, including providers capable of ECMO cannulation in the field as an effort to improve the ECPR outcomes, have been conducted [15].

\section{CA INCIDENCE AND SURVIVAL}

In the United States, the estimated annual incidences of IHCA and OHCA are 300,000 and 350,000-400,000, respectively. Globally, measures of incidence are lacking and vary significantly due to regional differences, for example, between developed and developing nations and rural and urban areas, with variable recordings of CA and outcomes. Multiple regional efforts are underway to determine the incidence and standardize the reporting of CA to more accurately measure survival and other outcomes [16-26]. In the United States, up to $25 \%$ of cases survive up to hospital discharge after IHCA, with the majority having favorable neurologic recovery demonstrated by a cerebral performance score (CPC) of 1 or $2[14,16,27]$. However, a recent meta-analysis reported only a $13 \%$ 1-year survival after IHCA [28]. OHCA survival is difficult to estimate because several patients are deceased before transport to the hospital, limiting the accurate recording of OHCA numbers. A review of emergency medical services (EMS) records indicates that approximately $6 \%-10 \%$ of patients who visit the hospital survive up to discharge [16-21].

\section{ECPR INDICATIONS AND ELIGIBILITY}

Although the optimal application of ECPR has not been established, the published literature has similar inclusion and exclusion criteria with limited data. The implementation of ECPR requires the rapid assembly and coordination of a specialized team, including members capable of cannulating ECMO, a perfusionist or specialist to monitor the ECMO circuit and flows, and trained nursing support. Appropriate patient selection relies on timely assessments and effective communication from the resuscitation team, including appropriate identification of ECPR-eligible patients, as well as determining the timing for transition to ECMO cannulation and transport during cardiopulmonary resuscitation (CPR).

For eligibility, there is a paucity of data to support age cutoffs in selecting ECMO candidates. Age of $<70$ years is recommended by the ELSO based on retrospective data and $<75$ years by some experienced regional centers with OHCA ECPR protocols [2933]. Patients should have a minimum no-flow time, defined as the time between CA and the initiation of CPR. The goal is to have a no-flow time of $<5$ minutes, which may depend on the presence of a witnessed CA and bystander CPR before the arrival of EMS for OHCA. The target time from CA to the initiation of ECMO (low-flow time) was $<60$ minutes [30].

An initial rhythm of ventricular fibrillation (VF) or ventricular tachycardia (VT) is suggestive of a primary reversible cardiac etiology for CA, and OHCA patients can be considered for early transportation to an ECPR-capable center if VT/VF is refractory after three shocks $[30,31,33]$. This strategy allows early identification and transport of patients to an ECPR-capable facility with continued CPR and pre-notification to the cardiac catheterization laboratory to prepare for immediate ECMO cannulation and cardiac catheterization. For patients with IHCA, ECMO cannulation can be considered after CA refractory to 10-20 minutes of CCPR if there is a suspected reversible etiology or after three shocks for VT/VF. Markers of perfusion that may aid in patient selection include those with end-tidal $\mathrm{CO}_{2}$ of $>10 \mathrm{mmHg}$ measured during CPR by capnography, $\mathrm{PaO}_{2}$ of $>55 \mathrm{mmHg}\left(\mathrm{O}_{2}\right.$ saturation $>85 \%$ ), and lactate of $<18 \mathrm{mmol} / \mathrm{L}$. However, they are often not available before cannulation, and there are limited data on their association with outcomes $[15,31,34,35]$. The exclusion criteria 
included significant comorbidities such as terminal disease, advanced cancer, advanced neurological disease, and low-performance status before CA $[30,31]$.

The optimal timing for the transition from CCPR to ECPR has not yet been established. Careful consideration and further research are necessary to determine the ideal ECPR eligibility and timing to improve outcomes and minimize unnecessary ECMO cannulation. A retrospective analysis of OHCA demonstrated benefits related to survival and neurologic outcomes measured by CPC at 3 months beginning after CPR for 21 minutes with propensity-matched patients having improved outcomes if they were treated with ECPR, compared with CCPR, if the duration was $>21$ minutes and no survival benefit if initiated earlier [36]. As the use of ECPR increases, early detection of acute brain injury $(\mathrm{ABI})$ and the improvement of neurological outcomes are crucial in improving overall outcomes in this population. Fig. 1 outlines the proposed mechanisms of $\mathrm{ABI}$ in patients after ECPR.

\section{SOCIETY GUIDELINES ON ECPR}

In 2020, the American Heart Association stated that there was insufficient evidence in support of the routine use of ECPR, but the therapy may be considered in select patients with suspected reversible etiology of CA [37]. In 2021, the European Resuscitation Council weakly recommended the consideration of ECPR for cases of refractory CA because of the low level of evidence [38]. None of the organizations provided specific indications for ECPR. The ELSO recently published a consensus statement for ECPR. Although ELSO did not provide specific guidelines or inclusion criteria due to the lack of strong evidence, they highlighted the importance of appropriately trained healthcare providers, teamwork, and planning. The ELSO recommended regional inclusion criteria, including resource availability and capability, to maximize favorable neurologic outcomes. They provided sample inclusion criteria, which included age of $<70$ years, witnessed $\mathrm{CA}$, arrest to CPR (no-flow time) of $<5$ minutes, initial rhythm

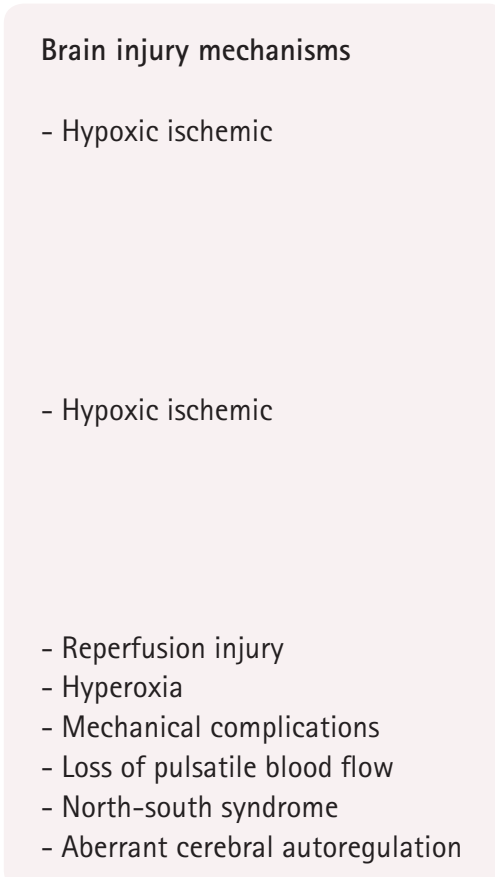

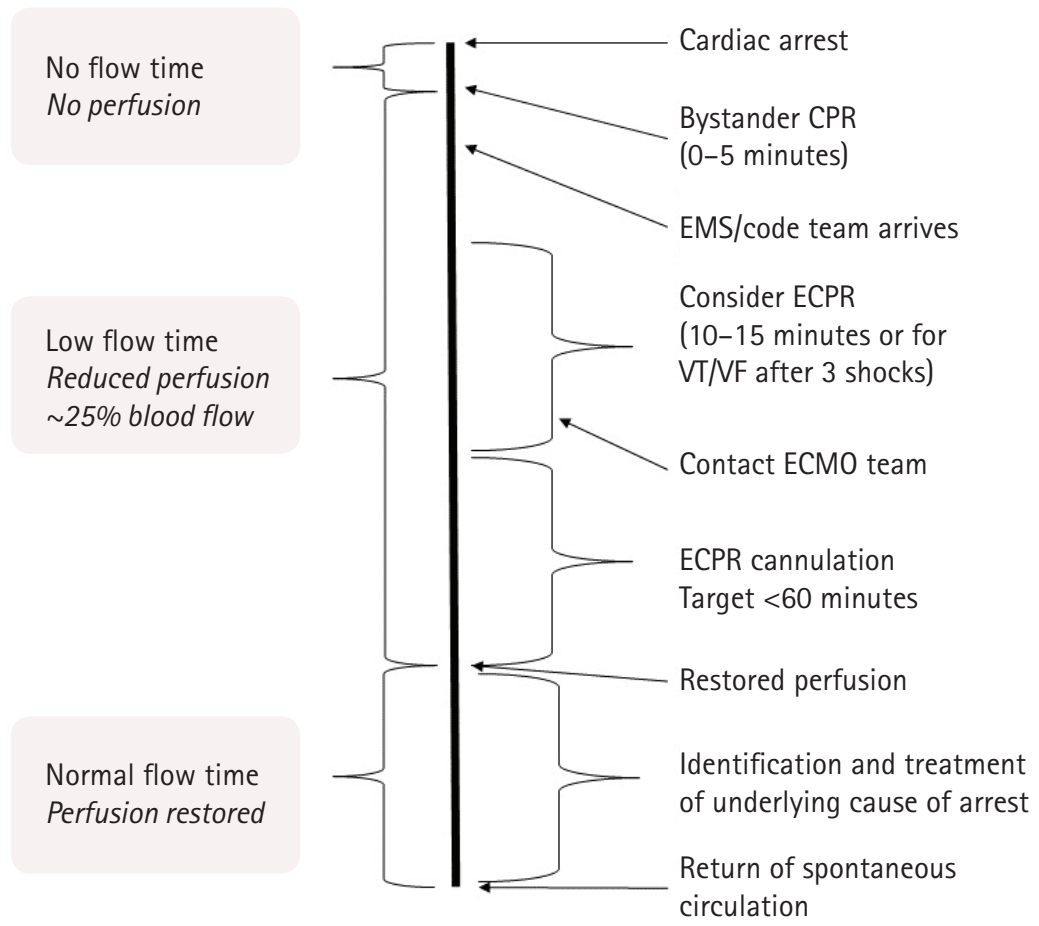

Fig. 1. Extracorporeal cardiopulmonary resuscitation (ECPR) model with associated risk factors for brain injury. This figure represents the model for the proposed timing for ECPR. ECPR should be considered if return of spontaneous circulation (ROSC) is not obtained within 10-15 minutes or after 3 shocks for ventricular tachycardia (VT)/ventricular fibrillation (VF). The cannulation goal is $<60$ minutes. Perfusion is restored after cannulation; however, ROSC may not be achieved until the underlying cause is addressed. The left column shows proposals of brain injury mechanisms during different stages of resuscitation. Flow time refers to duration in minutes. Bystander cardiopulmonary resuscitation (CPR) refers to life support measures initiated by on-scene persons before the arrival of emergency medical services (EMS) or health care agents before the arrival of the code team. ECMO, extracorporeal membrane oxygenation. 
$\mathrm{VT} / \mathrm{VF}$, pulseless electrical activity for IHCA, end-tidal $\mathrm{CO}_{2}$ of $>10 \mathrm{mmHg}$ during $\mathrm{CPR}$, absence of life-limiting comorbidity, and absence of known aortic valve incompetence $[12,30]$. The current guidelines do not provide standard neurological definitions and monitoring and management recommendations.

\section{SURVIVAL AND OUTCOMES AFTER ECPR}

Survival of up to $30 \%$ of appropriately selected patients after CA refractory to CCPR treated with ECPR has been reported $[12,39]$. However, there is significant variability in survival based on the location of CA, with one study reporting 50\% survival if CA occurred in or near a cardiac catheterization lab and $15 \%$ for other locations [11]. A recent randomized controlled trial, the Advanced reperfusion strategies for patients with out-of-hospital cardiac arrest and refractory ventricular fibrillation (ARREST): a phase 2, single centre, open-label, randomized controlled trial, compared ECPR and CCPR for OHCA with VF or VT rhythms persisting after three defibrillations. The trial was discontinued early with a significant survival benefit of ECPR over CCPR (43\% vs. 7\%) [30]. The ARREST trial demonstrated that a streamlined systematic approach in a high-volume ECMO center with experienced staff could dramatically improve the ECPR outcomes; however, the results of this study lack generalizability and should be validated in other centers with larger samples [40].

Among survivors of CA, long-term neurological sequelae, such as cognitive impairment and difficulties in performing activities of daily life, are common. The prevalence of hypoxic-ischemic brain injuries (HIBIs) in OHCA is higher with CCPR than with ECPR among survivors (50\% vs. $23 \%$ ) $[41,42]$. Although several of these survivors continue to improve toward near or complete functional independence in the long term, they still have a poor quality of life [43-45]. Despite the survival benefits and possibly improved neurological outcomes with ECPR, compared with CCPR, there are sparse data on the long-term function and quality of life of ECPR survivors $[13,14,40]$. As the data on ABI after ECPR accumulate, it is important to study the long-term neurological outcomes in this population.

\section{RANDOMIZED CLINICAL TRIALS}

The ARREST trial was a phase 2 open-label randomized clinical trial (RCT) of ECPR compared with CCPR in OHCA patients who presented initially with VF or VT. Participants were eligible if their dysrhythmia was refractory to three defibrillation shocks and were randomized to continue CCPR or ECPR. The trial was discontinued early after the pre-specified analysis showed clear superiority in the ECPR arm. The survival rate was $43 \%$ at discharge, and all patients were alive at 6 months with favorable CPC scores, with medians of 2.5 at discharge and 1.2 at 6 months, respectively, in the patients receiving ECPR. In contrast, patients in the CCPR group had a $0 \%$ survival within 6 months [40]. Another RCT, the Prague OHCA study (NCT 01511666), compared the standard care of CPR in the field with immediate transport using CPR assisted with a mechanical device for chest compressions followed by ECPR upon arrival at the hospital if return of spontaneous circulation (ROSC) was not obtained. Survival at 180 days was not significantly different (CCPR, $22 \%$ vs. ECPR, $31.5 \%)$; however, neurologic recovery at 30 days was significantly improved in the ECPR group ( $22.7 \%$ vs. $34.7 \%$ ) as was survival in the group with prolonged CA ( $>45$ minutes) receiving $\mathrm{CPR}$ [46]. Despite these encouraging outcomes, these findings need to be replicated with multicenter RCTs to validate the findings and possibly generalize to different populations. Other ongoing RCTs evaluating ECPR at the time of this article include the APACAR2 trial (NCT02527031), the Extracorporeal Cardiopulmonary Resuscitation for Refractory Out-of-Hospital Cardiac Arrest (EROCA): Results of a Randomized Feasibility Trial of Expedited Out-of-Hospital Transport (NCT03065647), and the Early Initiation of Extracorporeal Life Support in Refractory OHCA (INCEPTION) trial (NCT03101787) [47].

\section{ABI IN ECPR: MECHANISTIC CONSIDERATION}

\section{Hypoxic-ischemic injury and reperfusion injury}

HIBIs from the cessation of blood flow after CA is a leading cause of morbidity and mortality in CA survivors and has been reported in $23 \%$ of patients treated with ECPR $[42,48,49]$. This primary injury is followed by secondary ABI after ROSC because adequate blood supply is restored, leading to the formation of reactive oxygen species (ROS), alteration in microvasculature blood flow, and reperfusion injury [48,50-52]. These insults may be compounded by prolonged resuscitation and immediate restoration of oxygenated cerebral blood flow during ECPR.

The abatement of these injuries with targeted temperature management (TTM) by induction of mild hypothermia $\left(32^{\circ} \mathrm{C}-\right.$ $34^{\circ} \mathrm{C}$ ) in survivors of CA has been shown in multiple RCTs to improve survival and neurologic outcomes $[53,54]$. The ECMO circuit allows for rapid cooling for TTM, and the feasibility of cooling within minutes has been demonstrated in an adult swine model $[55,56]$. Survival benefits were demonstrated for TTM after ECPR; however, this was a single-center observational study, and other studies have found no benefit. Overall, there are no 
high-quality data on the impact of TTM on ECPR outcomes $[53,54,57]$. An additional consideration for TTM in this population is that ECMO-associated coagulopathy may be exacerbated by lower temperature targets and the need for systemic anticoagulation.

Retrospective studies of increased mean arterial pressure (MAP; > $80 \mathrm{mmHg}$ ) after CA have demonstrated improved survival and neurologic outcomes after CA. However, clear benefits have not been found in RCTs, and the most recent American Heart Association guidelines state that targeting MAP of $>80$ mmHg may be beneficial, but data are lacking $[37,58,59]$. In the setting of ECPR, the addition of anticoagulation to prevent circuit clotting increases the risk of hemorrhage, especially in patients with a significant burden of HIBIs with fresh cerebral infarcts. Therefore, optimal blood pressure management is unknown and MAP of $>65 \mathrm{mmHg}$ may be recommended to ensure adequate cerebral perfusion without a significantly increased risk of intracerebral hemorrhage and minimize the increased afterload created by ECMO flow against native heart blood flow.

\section{Hyperoxia and ROS}

Oxygen therapy plays a paramount role in the success of CPR after CA. However, excessive oxygenation or hyperoxia (commonly defined as mild $\mathrm{PaO}_{2}>100$ or $120 \mathrm{mmHg}$ and severe $\mathrm{PaO}_{2}>300$ $\mathrm{mmHg}$ ) after ROSC can lead to ABI. The detrimental effect of hyperoxia on $\mathrm{ABI}$ has been demonstrated in several different diseases, including traumatic brain injury, ischemic and hemorrhagic stroke, aneurysmal subarachnoid hemorrhage, and HIBIs. The underlying mechanism of $\mathrm{ABI}$ is an insult by ROS to the lipid membrane, deoxyribonucleic acid, and proteins.

Additionally, in CA, prolonged periods of ischemia deplete cells of adenosine triphosphate (ATP), preventing the recycling of reducing agents that neutralize ROS [60]. A decrease in the production of ATP also disrupts $\mathrm{Na}^{+} / \mathrm{K}^{+}$ATPase, which is responsible for maintaining membrane potential in neurons and leads to a $\mathrm{Ca}^{2+}$ influx that causes the release of cytochrome $\mathrm{c}$, leading to neuronal cell death via apoptosis. During ECPR, ECMO provides immediate cerebral blood flow restoration, which may exacerbate reperfusion injury in patients who are vulnerable to HIBIs with a global cerebral ischemic insult. Furthermore, ECMO decannulation is known to induce a systemic inflammatory response syndrome response, leading to further production of ROS and compounding the potential for secondary $\mathrm{ABI}[61]$.

\section{Animal CA and ECMO models on "hyperoxia"}

Established canine models of VF-induced CA lasting for $10 \mathrm{~min}$ utes followed by ROSC, were divided into normoxia $\left(\mathrm{PaO}_{2}, 80\right.$
$120 \mathrm{mmHg})$ and hyperoxia $\left(\mathrm{PaO}_{2}>120 \mathrm{mmHg}\right)$ groups. ROS formation increased in a dose-dependent manner with an increase in the $\mathrm{PaO}_{2}$ level. This correlated with increased disruption of the mitochondrial pyruvate dehydrogenase complex, an enzyme that produces reducing agents to nullify ROS in hyperoxia compared with normoxia groups. Postmortem examination demonstrated that the cerebral cortex and hippocampal neurons had increased disruption of pyruvate dehydrogenase complex and cell death specifically in neuronal Purkinje cells. Although both normoxia and hyperoxia increased inflammatory activation of microglial cells and macrophages, Purkinje cell loss was greater in the hyperoxia group [62]. Similar results were observed in a rat model of global cerebral ischemia, where normoxia was compared with hyperoxia after 10 minutes of bilateral carotid occlusion. At 7 and 30 days postintervention, more hippocampal neurons remained normal on histological examination in normoxic rats and hyperoxic rats [63].

In an ECMO model of global hypoxia, adult New Zealand White rabbits were cannulated with veno-venous (VV)- and veno-arterial (VA)-ECMO and subsequently hypoventilated to a $\mathrm{PaO}_{2}$ of $27 \mathrm{mmHg}$ and a $\mathrm{pH}$ of $<7.0$ and injected with bacterial endotoxin. The ECMO circuit was utilized to reoxygenate after the hypoxic event with $100 \%$ sweep oxygen compared with the control, which was reoxygenated through ventilation. Both VV and VA-ECMO groups demonstrated significantly increased concentrations of malondialdehyde, a byproduct of lipid damage by ROS and a marker of oxidative injury, both in the lung tissue and plasma compared with the control. This suggests that reperfusion via the ECMO circuit after a global hypoxic event increases ROS and lipid membrane peroxidation, which can lead to alveolar damage $[64,65]$. Table 1 summarizes the established animal models of ECPR.

\section{Clinical research on "hyperoxia" in ECPR}

Recently, the Conservative Oxygen Therapy during Mechanical Ventilation in the intensive care unit (ICU-ROX) study aimed to determine the benefits of conservative oxygen treatment and compare them with usual oxygen treatment for any mechanically ventilated patient in need of $>24$ hours of mechanical ventilation in the ICU [66]. The study compared the goal-directed oxygen treatment $\left(\mathrm{FiO}_{2}\right.$ decreased to 0.21 as soon as possible with an upper limit alarm set for $\mathrm{SpO}_{2} \geq 97 \%$ ) to the usual oxygen treatment (standard care with no specific measures limiting $\mathrm{FiO}_{2}$ or $\mathrm{SpO}_{2}$ ) and found no difference in the number of ventilator-free days. However, in the subgroup analysis of patients with suspected HIBIs, mortality differed significantly between the goal-directed (conservative) oxygen group and the usual (standard) oxygen 


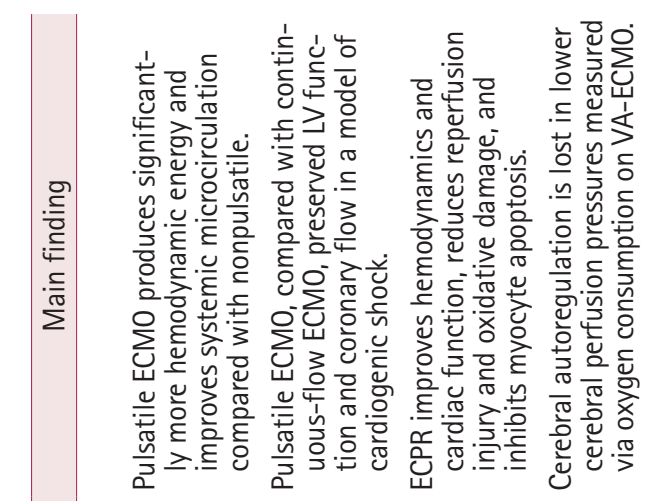

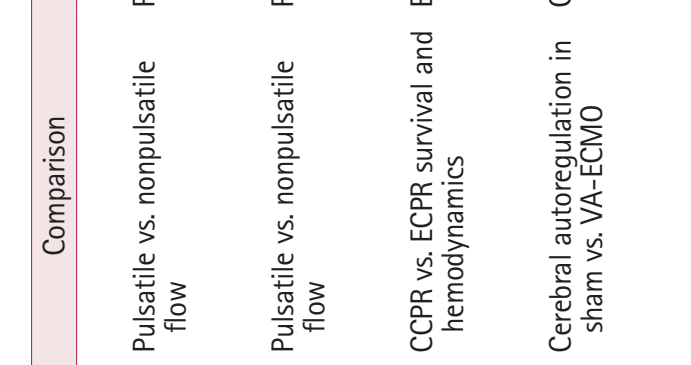

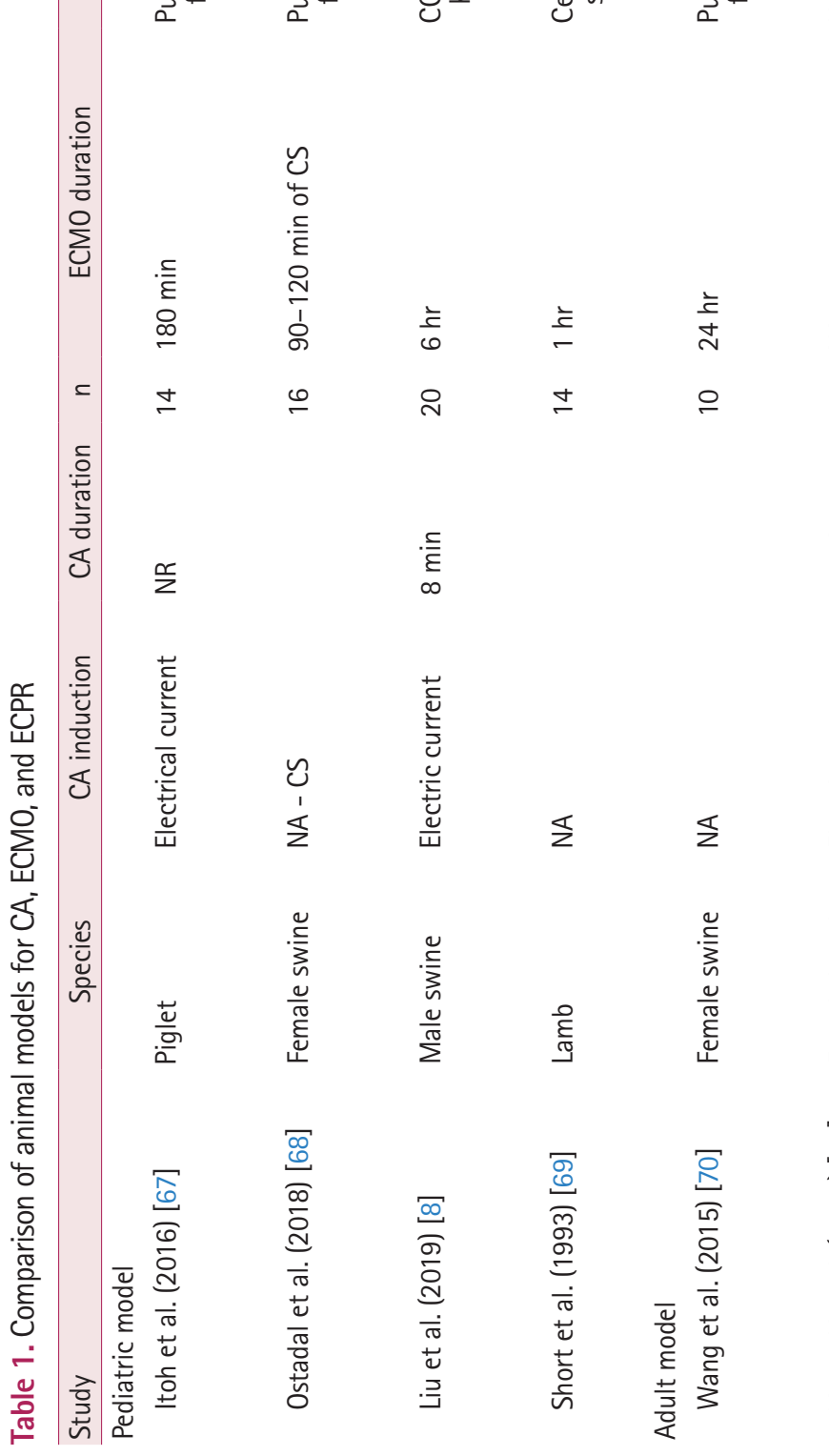

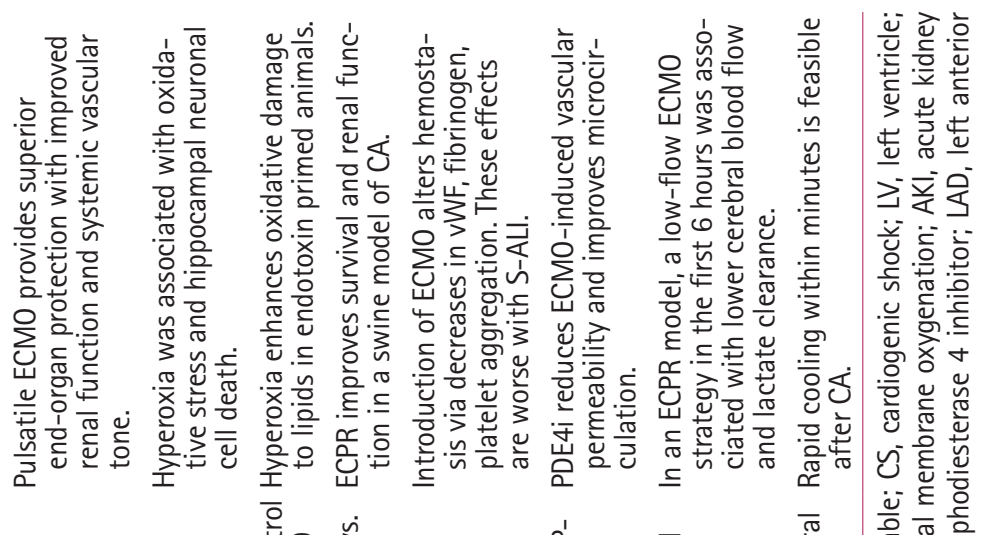

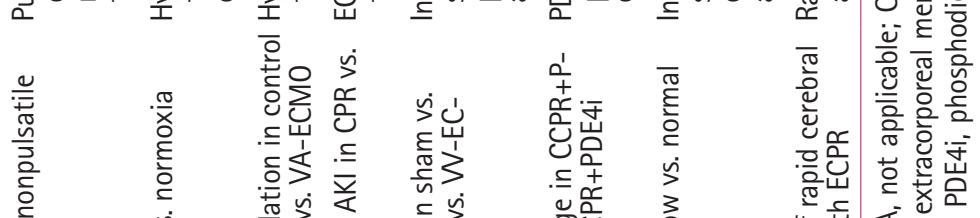

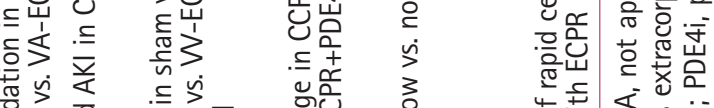

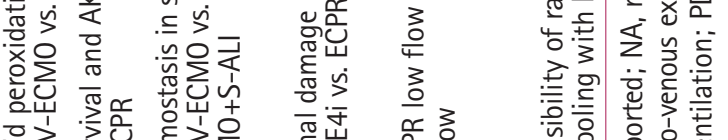

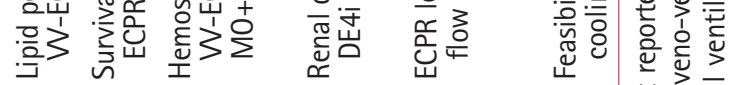

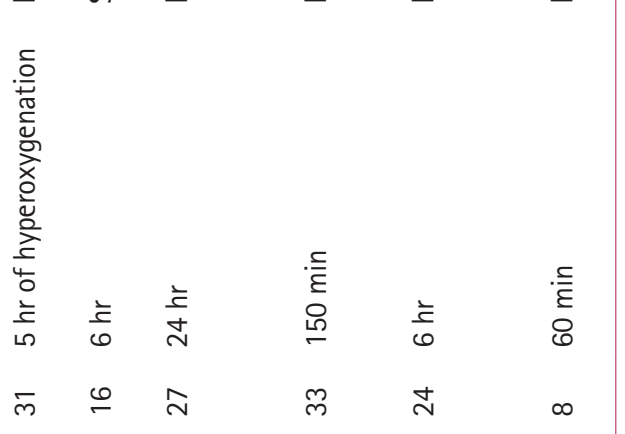

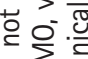

败焉 宁

莺

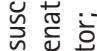

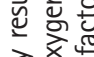

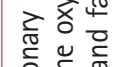

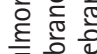

흥 है해

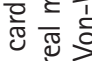

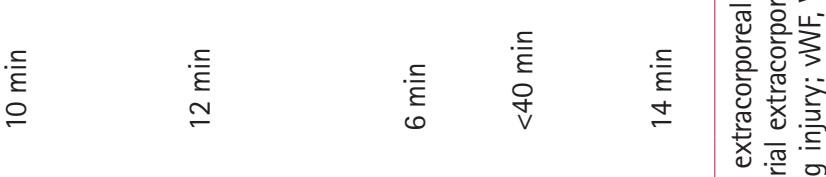

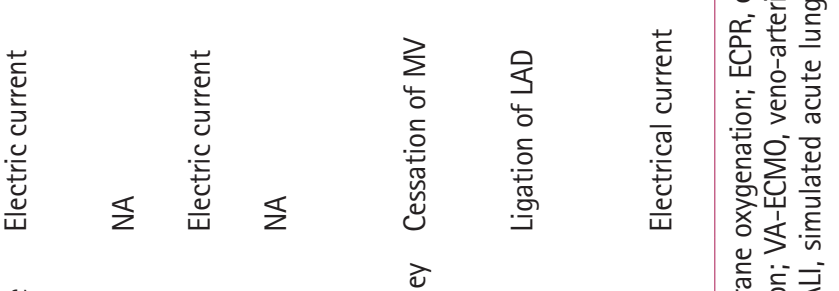

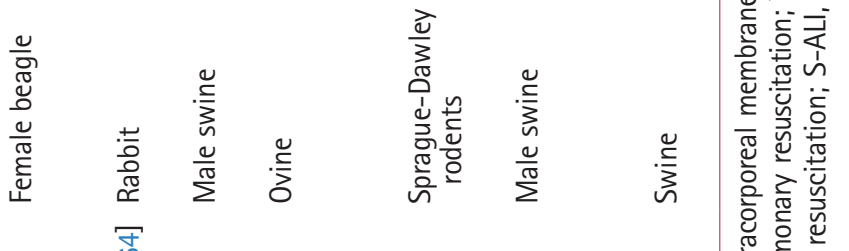

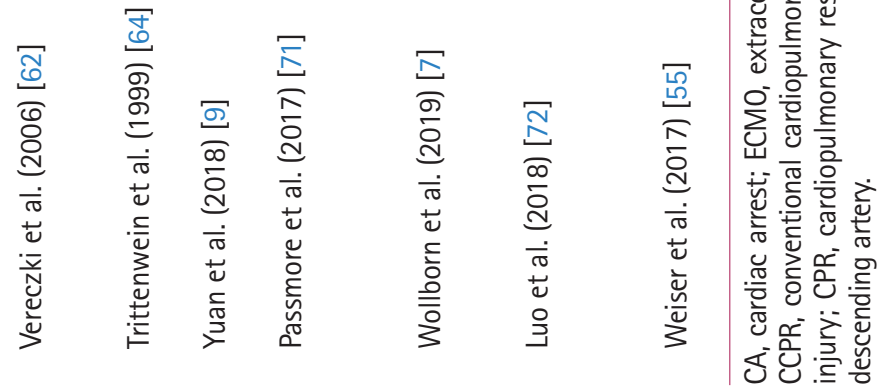


group ( $43 \%$ vs. $59 \%$; reparatory rate, 0.73 ; $95 \%$ confidence interval, 0.54-0.99), highlighting the potential benefits of avoiding hyperoxia in patients at risk of brain ischemia. However, the effect of hyperoxia on ECPR patients remains unclear. In pediatric studies that have examined this specific question, moderate hyperoxia during the first 48 hours was an independent risk factor for increased mortality [73]. In a prior analysis of the ELSO registry from 2010 through 2015, hyperoxia, defined as a $\mathrm{PaO}_{2}>100$ $\mathrm{mmHg}$ at 24 hours, was associated with increased mortality in patients treated with VA-ECMO [74]. A second prospective single-center analysis identified that hyperoxia $\left(\mathrm{PO}_{2}>300 \mathrm{mmHg}\right)$ during the first hour after resuscitation was associated with a worse neurologic outcome at discharge [75]. A recent analysis of 10,342 VA-ECMO patients from the ELSO showed that all subtypes of $\mathrm{ABI}$ were more common in patients with hyperoxia, as measured by 24-hour ABG [76]. However, data on this for ECPR patients are limited.

\section{Animal models of nonpulsatile blood flow and cerebral autoregulation in ECMO}

The loss of pulsatile blood flow occurs as a consequence of continuous flow ECMO systems and has been linked to endothelial dysfunction, increased sympathetic tone, decreased local oxygen consumption, and increased systemic vascular resistance [77-79]. An adolescent swine cardiogenic shock model was placed on VA-ECMO with a pulsatile (utilizing an electrocardiogram synchronized system) or nonpulsatile circuit, and cardiogenic shock was induced via balloon occlusion of the left main coronary artery $[70,80]$. ECMO flow was increased in a stepwise manner with intravascular measurement catheters showing significantly higher cardiac output, coronary artery blood flow, and MAP in patients with pulsatile blood flow than in those with nonpulsatile flow [68].

In a cerebral autoregulation model, newborn lambs were separated into the VA-ECMO group $(\mathrm{n}=7)$ or controls with right carotid artery and jugular vein ligation $(n=7)$ and had an intracranial catheter inserted to manipulate cerebral perfusion pressure (CPP). Cerebral blood flow was maintained at lower CPPs in the control group, suggesting a loss of protective antiregulatory mechanisms in animals treated with VA-ECMO [69].

\section{Loss of pulsatile flow and autoregulation in cardiac surgery}

Pulsatile and nonpulsatile CPB flows were compared in 32 adult patients undergoing open-heart surgery with CPB. Cerebral blood flow velocity was measured using stereotactic transcranial Doppler (TCD) monitoring of the middle cerebral artery. Normal vasodilatory and constrictive responses to $\mathrm{CO}_{2}$ in the non- pulsatile group were blunted compared to the pulsatile flow, suggesting a loss of cerebral autoregulation in response to changes in $\mathrm{CO}_{2}$ with the loss of pulsatile blood flow [81]. In patients placed on $\mathrm{CPB}$ for surgery, the microcirculation of sublingual tissue was compared with pulsatile and nonpulsatile flow using a previously established noninvasive spectral imaging technique [82].

At the microcirculation level, disrupted perfusion and leukocyte activation in sublingual tissue were observed in the nonpulsatile group, compared with the pulsatile group. This effect was statistically significant, and it increased in magnitude with $\mathrm{CPB}$ time and was associated with lower lactate in the pulsatile flow group, suggesting an aberrant antiregulatory response with the loss of pulsatile flow [78]. In patients with implanted left ventricular assist devices, pulsatile flow devices (vs. nonpulsatile devices) showed significant reductions for stroke ( $9.9 \%$ vs. $19.4 \%)$ and disabling ischemic stroke (3.9\% vs. $5.9 \%$ ) two years post-implantation [83]. Non-pulsatile blood flow may impair cerebral autoregulation, reducing the normal protective response of cerebral vessels to changes in $\mathrm{CPP}$ and $\mathrm{CO}_{2}$ and further increasing the risk of $\mathrm{ABI}$ after $\mathrm{CA}$; the feasibility and benefit of pulsatile flow during VA-ECMO and ECPR have yet to be established, but it warrants consideration as a mechanism for reducing $\mathrm{ABI}$.

\section{Animal model of impaired coagulation in ECMO}

One animal model examined coagulopathy in adult sheep exposed to smoke-induced lung injury by comparing animals placed on VV-ECMO to controls (mechanical ventilation only). During 24 hours of ECMO flow, there was an increase in collagen-induced platelet aggregation, increased platelet aggregation time, and decreased clot firmness as measured by thromboelastography. Additionally, fibrinogen, factor VIII, and von Willebrand factor were all reduced in animals treated with VV-ECMO and were synergistically worse when combined with smoke-induced lung injury than in controls. This model suggests that abnormal platelet aggregation and decreased clot effectiveness in ECMO may predispose patients to coagulopathy, increasing the risk of thrombosis and bleeding [71].

\section{Ischemic stroke and intracranial hemorrhage in VA-ECMO}

In addition to HIBIs, acute ischemic stroke (AIS) and intracranial hemorrhage (ICH) are major complications that increase mortality in patients supported with ECMO $[76,84,85]$. In patients treated with VA-ECMO, the prevalence of AIS is $3.3 \%$ and may be as high as $16 \%$ on autopsy $[86,87]$. The risk factors for AIS include circuit clots (oxygenator clot), left ventricle (LV) thrombus, and insertion of ECMO catheters [86,88-90]. The prevalence of 
ICH with VA-ECMO is reported to be between $2 \%$ and $18 \%$ and as high as $24 \%$ on autopsy $[86,87]$. Thrombocytopenia and heparin use pre-dispose to $\mathrm{ICH}$ and rapid hematoma expansion, which may be exacerbated by impaired coagulation function in ECMO patients [71,91,92].

Cerebral microbleeds (CMBs) were detected in $60 \%$ of patients treated with ECMO at autopsy and in 50\% of survivors from a retrospective analysis, both of which are much higher than the rates in the general population $[93,94]$. Several other case series and retrospective observational studies also reported CMBs in patients treated with ECMO with unknown clinical significance or long-term outcomes [95-97]. CMBs may indicate ongoing cerebral small vessel disease in patients treated with ECMO, but their significance and etiology remain to be elucidated.

\section{Harlequin syndrome}

Harlequin syndrome, also described as the North-south syndrome, dual circulation, and differential hypoxia, is a phenomenon that occurs in peripherally cannulated VA-ECMO patients with respiratory failure and cardiac failure, such that they are unable to adequately oxygenate blood. The ECMO venous catheter drains oxygen from the inferior vena cava and returns oxygenated blood from the ECMO circuit to the aorta, which meets with the blood ejected from the LV that is recovering. This blood preferentially circulates towards the lower extremities and returns via the inferior vena cava, where it is recirculated through the ECMO circuit. Deoxygenated blood, due to pulmonary dysfunction, ejected from the LV may preferentially perfuse the aortic arch in an antegrade fashion, thereby perfusing the head vessels with deoxygenated blood as it competes with the oxygenated retrograde arterial blood flow from the femoral artery cannula. This mismatch of upper body hypoxia coupled with lower body normoxia, hence differential hypoxia, is called Harlequin syndrome [98-100]. Hypoperfusion and ischemia of the brain and heart are associated with HIBIs. The prevalence is reported to be approximately 9\%; therefore, it is critical to monitor arterial blood gas values from the patient's right radial artery, the most distal arterial access from the femoral artery cannula, to gain insights into the oxygenation status of the upper torso [101].

\section{NEUROLOGIC MONITORING FOR ABI IN ECPR}

Accurate estimation of the prevalence of $A B I$ associated with ECPR is difficult due to limitations in neurological examination with the use of sedatives as well as safety concerns in performing neuroimaging studies during ECMO support. Magnetic resonance imaging is currently precluded because of the ECMO circuit [102]. Even if head computed tomography (HCT) is performed, the utility of HCT in detecting early ischemia and lesions in the posterior circulation territory is limited. Other noninvasive neurological monitoring methods include TCD, somatosensory evoked potentials, cerebral near-infrared spectroscopy (cNIRS), and electroencephalography (EEG), which may systematically assess the occurrence of ABI [103-105]. Another useful tool for noninvasive monitoring is optic nerve sheath diameter measurement with ultrasound, which may provide information on intracranial pressure [102]. A standard neurological monitoring protocol can increase sensitivity in the detection of ABI [103]. TCD may have a role in detecting ECMO circuit clots, such as arterial-sided oxygenator clots, which may be associated with ischemic stroke [89]. In addition, TCD can be used to detect ongoing cerebral microembolic signals while on ECMO, but further study is necessary to establish a firm relationship between AIS and TCD microembolic signals [106]. cNIRS may be a useful real-time bedside neuromonitoring tool to detect $\mathrm{ABI}$ in ECMO patients when an acute drop in regional oxygenation saturation occurs [107]. It is recommended to monitor patients after CA with continuous EEG (cEEG) [108]. Similarly, ECPR patients should be monitored with cEEG, as patients are at a high risk of seizures. Furthermore, EEG features such as absent EEG reactivity and discontinuous background may be associated with poor outcomes in comatose ECMO patients $[109,110]$. Therefore, cEEG monitoring is recommended for ECMO patients with disorders of consciousness off sedation and somatosensory evoked potentials for patients with motor Glasgow Coma Scale scores of $<4[103,104]$. Optic nerve sheath diameter can be abnormal due to ABI but is less useful in the prevention of injury [111]. Each of these neurological monitoring tools has limitations. Therefore, a standardized multimodal neuromonitoring approach, as well as clinical neurological assessment with neurological consultation, may facilitate early detection of ABI associated with ECPR. However, the effectiveness of this approach in improving outcomes by primary and secondary prevention or providing reliable neurological prognostic information is yet to be established [103]. Fig. 2 summarizes the neurological complications, monitoring, and prognostication of ECPR.

\section{BIOMARKERS IN ECPR}

Several biomarkers have been identified and associated with ABI in patients treated with ECMO. These include markers of neuronal injury (neuron-specific enolase [NSE] and intercellular adhe- 


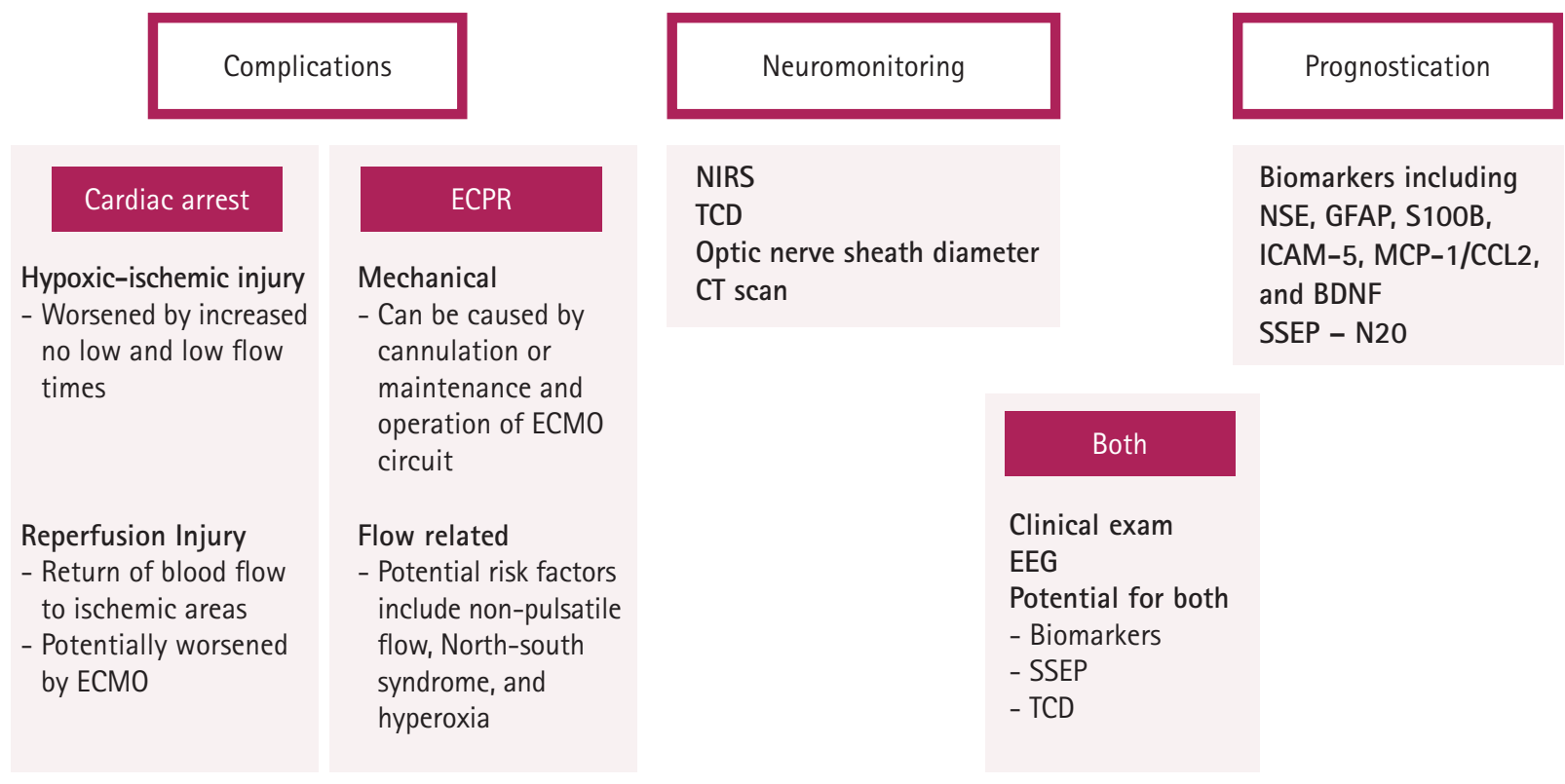

Fig. 2. Components of neurologic complications, monitoring, and prognostication in extracorporeal cardiopulmonary resuscitation (ECPR). NIRS, near-infrared spectroscopy; TCD, transcranial Doppler; CT, computed tomography; NSE, neuron-specific enolase; GFAP, glial fibrillary acidic protein; $\mathrm{S100B}$, calcium-binding protein $\mathrm{B}$; ICAM-5, intercellular adhesion molecule 5; MCP-1/CCL2, monocyte chemoattractant protein 1/chemokine (C-C motif) ligand-2; BDNF, brain-derived neurotrophic factor; SSEP, somatosensory evoked potential; ECMO, extracorporeal membrane oxygenation; EEG, electroencephalography.

sion molecule 5), glial cell injury (glial fibrillary acidic protein [GFAP], calcium-binding protein B [S100B], and brain-derived neurotrophic factor), and neuronal inflammation (monocyte chemoattractant protein $1 /$ chemokine [C-C motif] ligand 2 [MCP1/CCL2]) [102]. In patients treated with ECPR, higher NSE has been shown to correlate with increased mortality and ABI; however, hemolysis is common in ECMO and may result in false positives in NSE measurement $[112,113]$. In patients with ABI associated with ECMO treatment, S100B was found to be significantly elevated, and in a separate case series of infants, it was significantly elevated 72 hours before ICH $[114,115]$. There is evidence that GFAP is associated with ICH, brain death, cerebral edema, and mortality and is elevated in children 1-2 days before the detection of ABI on imaging [116]. S100B and GFAP in combination may be representative predictive biomarkers for children as the levels were elevated 1-3 days before the detection of $\mathrm{ABI}[115,116]$. A marker of axonal injury in neurons, tau, measurable via serum assay may be significantly better than NSE for neuro prognostication after CA; however, there is a lack of data on the use of ECMO and EPCR [117]. Similarly, after $\mathrm{CA}$, another marker of axonal injury, the neurofilament light chain, is associated with HIBIs in children and poor long-term neurologic outcomes in adults $[118,119]$. Post-CA biomarkers have been shown to peak at different periods but they are not sensitive or specific enough to be independent prognostic markers [120]. For ECPR, biomarkers may aid in prognostication as part of the multimodal evaluation, including imaging and clinical assessments, to increase sensitivity.

\section{CONCLUSIONS}

ECPR represents advancement in CPR, allowing a bridge to therapy in appropriately selected patients after refractory CA. Currently, ECPR is most successful at centers with experienced staff or communities with an appropriately trained and experienced ECMO team. Although ECPR may improve survival, ABI remains the leading cause of morbidity and mortality among patients treated with ECPR. A standardized neuromonitoring protocol may improve $\mathrm{ABI}$ detection. A better understanding of the role of early hyperoxia, TTM, cerebral blood flow, and reperfusion injury is important for improving neurological outcomes of ECPR survivors. Furthermore, cerebral microcirculation and autoregulation with non-physiological blood flow in ECMO may play a critical role in cerebral small vessel disease. "Bench-to-Bedside" translational and clinical research on "ABI in ECMO" is necessary as the use of ECPR is increasing, as well as its associated increase in survival. 


\section{ARTICLE INFORMATION}

\section{Ethics statement}

Not applicable.

\section{Conflict of interest}

No potential conflict of interest relevant to this article.

\section{Acknowledgments}

The authors would like to thank to the Departments of Neurology, Neurosurgery, Anesthesiology, and Cardiothoracic Surgery of Johns Hopkins Hospital.

\section{ORCID}

Christopher Wilcox

https://orcid.org/0000-0002-8456-0552

Sung-Min Cho

https://orcid.org/0000-0002-5132-0958

\section{Author contributions}

Conceptualization: SMC, CJW. Data curation: NA. Formal analysis: NA. Funding acquisition: NA. Methodology: SMC, CJW. Project administration: SMC. Visualization: SMC, CJW. Writingoriginal draft: SMC, CJW. Writing-review \& editing: SMC, CJW, CWC.

\section{REFERENCES}

1. Kennedy JH. The role of assisted circulation in cardiac resuscitation. JAMA 1966;197:615-8.

2. Phillips SJ, Ballentine B, Slonine D, Hall J, Vandehaar J, Kongtahworn C, et al. Percutaneous initiation of cardiopulmonary bypass. Ann Thorac Surg 1983;36:223-5.

3. Mooney MR, Arom KV, Joyce LD, Mooney JF, Goldenberg IF, Von Rueden TJ, et al. Emergency cardiopulmonary bypass support in patients with cardiac arrest. J Thorac Cardiovasc Surg 1991;101:450-4.

4. del Nido PJ, Dalton HJ, Thompson AE, Siewers RD. Extracorporeal membrane oxygenator rescue in children during cardiac arrest after cardiac surgery. Circulation 1992;86(5 Suppl):II300-4.

5. Mégarbane B, Leprince P, Deye N, Résière D, Guerrier G, Rettab $\mathrm{S}$, et al. Emergency feasibility in medical intensive care unit of extracorporeal life support for refractory cardiac arrest. Intensive Care Med 2007;33:758-64.

6. Dembitsky WP, Moreno-Cabral RJ, Adamson RM, Daily PO. Emergency resuscitation using portable extracorporeal membrane oxygenation. Ann Thorac Surg 1993;55:304-9.

7. Wollborn J, Siemering S, Steiger C, Buerkle H, Goebel U, Schick
MA. Phosphodiesterase-4 inhibition reduces ECLS-induced vascular permeability and improves microcirculation in a rodent model of extracorporeal resuscitation. Am J Physiol Heart Circ Physiol 2019;316:H751-61.

8. Liu B, Zhang Q, Liang Y, Zhang Y, Yuan X, Ling J, et al. Extracorporeal membrane oxygenation mitigates myocardial injury and improves survival in porcine model of ventricular fibrillation cardiac arrest. Scand J Trauma Resusc Emerg Med 2019; 27:82.

9. Yuan XL, Li CS, Zhang Y, Ling JY, Zhang Q Liang Y, et al. Extracorporeal membrane oxygenation improving survival and alleviating kidney injury in a swine model of cardiac arrest compared to conventional cardiopulmonary resuscitation. Chin Med J (Engl) 2018;131:1840-8.

10. McCarthy FH, McDermott KM, Kini V, Gutsche JT, Wald JW, Xie D, et al. Trends in U.S. extracorporeal membrane oxygenation use and outcomes: 2002-2012. Semin Thorac Cardiovasc Surg 2015;27:81-8.

11. Yam N, McMullan DM. Extracorporeal cardiopulmonary resuscitation. Ann Transl Med 2017;5:72.

12. Extracorporeal Life Support Organization. ECMO registry of the Extracorporeal Life Support Organization (ELSO), 2020. Ann Arbor, MI: ELSO Registry; 2020.

13. Ahn C, Kim W, Cho Y, Choi KS, Jang BH, Lim TH. Efficacy of extracorporeal cardiopulmonary resuscitation compared to conventional cardiopulmonary resuscitation for adult cardiac arrest patients: a systematic review and meta-analysis. Sci Rep 2016;6:34208.

14. Kim SJ, Kim HJ, Lee HY, Ahn HS, Lee SW. Comparing extracorporeal cardiopulmonary resuscitation with conventional cardiopulmonary resuscitation: a meta-analysis. Resuscitation 2016;103:106-16.

15. Lamhaut L, Hutin A, Puymirat E, Jouan J, Raphalen JH, Jouffroy R, et al. A pre-hospital Extracorporeal Cardio Pulmonary Resuscitation (ECPR) strategy for treatment of refractory out hospital cardiac arrest: an observational study and propensity analysis. Resuscitation 2017;117:109-17.

16. Andersen LW, Holmberg MJ, Berg KM, Donnino MW, Granfeldt A. In-hospital cardiac arrest: a review. JAMA 2019;321: 1200-10.

17. Hayashi M, Shimizu W, Albert CM. The spectrum of epidemiology underlying sudden cardiac death. Circ Res 2015;116: 1887-906.

18. Myat A, Song KJ, Rea T. Out-of-hospital cardiac arrest: current concepts. Lancet 2018;391:970-9.

19. Myerburg RJ. Cardiac and noncardiac causes of apparent sudden arrhythmic deaths: shadows in a spectrum. Circulation 
2018;137:2701-4.

20. Virani SS, Alonso A, Benjamin EJ, Bittencourt MS, Callaway CW, Carson AP, et al. Heart disease and stroke statistics: 2020 update: a report from the American Heart Association. Circulation 2020;141:e139-596.

21. Nichol G, Thomas E, Callaway CW, Hedges J, Powell JL, Aufderheide TP, et al. Regional variation in out-of-hospital cardiac arrest incidence and outcome. JAMA 2008;300:1423-31.

22. Gräsner JT, Herlitz J, Tjelmeland IB, Wnent J, Masterson S, Lilja G, et al. European Resuscitation Council Guidelines 2021: epidemiology of cardiac arrest in Europe. Resuscitation 2021; 161:61-79.

23. Berdowski J, Berg RA, Tijssen JG, Koster RW. Global incidences of out-of-hospital cardiac arrest and survival rates: systematic review of 67 prospective studies. Resuscitation 2010;81:1479-87.

24. Ong ME, Shin SD, Tanaka H, Ma MH, Khruekarnchana P, Hisamuddin N, et al. Pan-Asian Resuscitation Outcomes Study (PAROS): rationale, methodology, and implementation. Acad Emerg Med 2011;18:890-7.

25. Ong ME, Shin SD, De Souza NN, Tanaka H, Nishiuchi T, Song $\mathrm{KJ}$, et al. Outcomes for out-of-hospital cardiac arrests across 7 countries in Asia: the Pan Asian Resuscitation Outcomes Study (PAROS). Resuscitation 2015;96:100-8.

26. Doctor NE, Ahmad NS, Pek PP, Yap S, Ong ME. The Pan-Asian Resuscitation Outcomes Study (PAROS) clinical research network: what, where, why and how. Singapore Med J 2017;58: 456-8.

27. The Brain Resuscitation Clinical Trial II Study Group. A randomized clinical trial of calcium entry blocker administration to comatose survivors of cardiac arrest. Design, methods, and patient characteristics. Control Clin Trials 1991;12:525-45.

28. Schluep M, Gravesteijn BY, Stolker RJ, Endeman H, Hoeks SE. One-year survival after in-hospital cardiac arrest: a systematic review and meta-analysis. Resuscitation 2018;132:90-100.

29. Goto T, Morita S, Kitamura T, Natsukawa T, Sawano H, Hayashi $\mathrm{Y}$, et al. Impact of extracorporeal cardiopulmonary resuscitation on outcomes of elderly patients who had out-of-hospital cardiac arrests: a single-centre retrospective analysis. BMJ Open 2018; 8:e019811.

30. Richardson AS, Tonna JE, Nanjayya V, Nixon P, Abrams DC, Raman L, et al. Extracorporeal cardiopulmonary resuscitation in adults: interim guideline consensus statement from the Extracorporeal Life Support Organization. ASAIO J 2021;67:221-8.

31. Yannopoulos D, Bartos JA, Martin C, Raveendran G, Missov E, Conterato $\mathrm{M}$, et al. Minnesota resuscitation consortium's advanced perfusion and reperfusion cardiac life support strategy for out-of-hospital refractory ventricular fibrillation. J Am Heart
Assoc 2016;5:e003732.

32. Bartos JA, Grunau B, Carlson C, Duval S, Ripeckyj A, Kalra R, et al. Improved survival with extracorporeal cardiopulmonary resuscitation despite progressive metabolic derangement associated with prolonged resuscitation. Circulation 2020;141:87786.

33. Sakamoto T, Morimura N, Nagao K, Asai Y, Yokota H, Nara S, et al. Extracorporeal cardiopulmonary resuscitation versus conventional cardiopulmonary resuscitation in adults with out-of-hospital cardiac arrest: a prospective observational study. Resuscitation 2014;85:762-8.

34. Napp LC, Sanchez Martinez C, Akin M, Garcheva V, Kühn C, Bauersachs J, et al. Use of extracorporeal membrane oxygenation for eCPR in the emergency room in patients with refractory out-of-hospital cardiac arrest. PLoS One 2020;15: e0239777.

35. Wang CH, Chou NK, Becker LB, Lin JW, Yu HY, Chi NH, et al. Improved outcome of extracorporeal cardiopulmonary resuscitation for out-of-hospital cardiac arrest: a comparison with that for extracorporeal rescue for in-hospital cardiac arrest. Resuscitation 2014;85:1219-24.

36. Kim SJ, Jung JS, Park JH, ParkJS, Hong YS, Lee SW. An optimal transition time to extracorporeal cardiopulmonary resuscitation for predicting good neurological outcome in patients with out-of-hospital cardiac arrest: a propensity-matched study. Crit Care 2014;18:535.

37. Panchal AR, Bartos JA, Cabañas JG, Donnino MW, Drennan IR, Hirsch KG, et al. Part 3: adult basic and advanced life support: 2020 American Heart Association Guidelines for cardiopulmonary resuscitation and emergency cardiovascular care. Circulation 2020;142(16_suppl_2):S366-468.

38. Lott C, Truhlár A, Alfonzo A, Barelli A, González-Salvado V, Hinkelbein J, et al. European Resuscitation Council Guidelines 2021: cardiac arrest in special circumstances. Resuscitation 2021;161:152-219.

39. Thiagarajan RR, Brogan TV, Scheurer MA, Laussen PC, Rycus PT, Bratton SL. Extracorporeal membrane oxygenation to support cardiopulmonary resuscitation in adults. Ann Thorac Surg 2009;87:778-85.

40. Yannopoulos D, Bartos J, Raveendran G, Walser E, Connett J, Murray TA, et al. Advanced reperfusion strategies for patients with out-of-hospital cardiac arrest and refractory ventricular fibrillation (ARREST): a phase 2, single centre, open-label, randomised controlled trial. Lancet 2020;396:1807-16.

41. Pusswald G, Fertl E, Faltl M, Auff E. Neurological rehabilitation of severely disabled cardiac arrest survivors. Part II. Life situation of patients and families after treatment. Resuscitation 
2000;47:241-8.

42. Migdady I, Rice C, Deshpande A, Hernandez AV, Price C, Whitman GJ, et al. Brain injury and neurologic outcome in patients undergoing extracorporeal cardiopulmonary resuscitation: a systematic review and meta-analysis. Crit Care Med 2020;48:e611-9.

43. Writing Group Members, Mozaffarian D, Benjamin EJ, Go AS, Arnett DK, Blaha MJ, et al. Heart disease and stroke statistics: 2016 update: a report from the American Heart Association. Circulation 2016;133:e38-360.

44. Raina KD, Rittenberger JC, Holm MB, Callaway CW. Functional outcomes: one year after a cardiac arrest. Biomed Res Int 2015;2015:283608.

45. de Vos R, de Haes HC, Koster RW, de Haan RJ. Quality of survival after cardiopulmonary resuscitation. Arch Intern Med 1999; 159:249-54.

46. Belohlávek J. Hyperinvasive approach in refractory out-of-hospital cardiac arrest. Prague OHCA study: a randomized clinical trial. Washington, DC: American College of Cardiology; 2021.

47. Bol ME, Suverein MM, Lorusso R, Delnoij TS, Brandon Bravo Bruinsma GJ, Otterspoor L, et al. Early initiation of extracorporeal life support in refractory out-of-hospital cardiac arrest: design and rationale of the INCEPTION trial. Am Heart J 2019; 210:58-68.

48. Sekhon MS, Ainslie PN, Griesdale DE. Clinical pathophysiology of hypoxic ischemic brain injury after cardiac arrest: a "twohit" model. Crit Care 2017;21:90.

49. Laver S, Farrow C, Turner D, Nolan J. Mode of death after admission to an intensive care unit following cardiac arrest. Intensive Care Med 2004;30:2126-8.

50. Madathil RJ, Hira RS, Stoeckl M, Sterz F, Elrod JB, Nichol G. Ischemia reperfusion injury as a modifiable therapeutic target for cardioprotection or neuroprotection in patients undergoing cardiopulmonary resuscitation. Resuscitation 2016;105:85-91.

51. Böttiger BW, Krumnikl JJ, Gass P, Schmitz B, Motsch J, Martin E. The cerebral 'no-reflow' phenomenon after cardiac arrest in rats: influence of low-flow reperfusion. Resuscitation 1997; 34:79-87.

52. Jean WC, Spellman SR, Nussbaum ES, Low WC. Reperfusion injury after focal cerebral ischemia: the role of inflammation and the therapeutic horizon. Neurosurgery 1998;43:1382-96.

53. Hypothermia after cardiac arrest study group. Mild therapeutic hypothermia to improve the neurologic outcome after cardiac arrest. N Engl J Med 2002;346:549-56.

54. Bernard SA, Gray TW, Buist MD, Jones BM, Silvester W, Gutteridge G, et al. Treatment of comatose survivors of out-of-hospital cardiac arrest with induced hypothermia. N Engl J Med
2002;346:557-63.

55. Weiser C, Weihs W, Holzer M, Testori C, Kramer AM, Kment $\mathrm{C}$, et al. Feasibility of profound hypothermia as part of extracorporeal life support in a pig model. J Thorac Cardiovasc Surg 2017;154:867-74.

56. Kim YS, Cho YH, Sung K, Ryu JA, Chung CR, Suh GY, et al. Target temperature management may not improve clinical outcomes of extracorporeal cardiopulmonary resuscitation.J Intensive Care Med 2019;34:790-6.

57. Kagawa E, Dote K, Kato M, Sasaki S, Oda N, Nakano Y, et al. Do lower target temperatures or prolonged cooling provide improved outcomes for comatose survivors of cardiac arrest treated with hypothermia? J Am Heart Assoc 2015;4:e002123.

58. Beylin ME, Perman SM, Abella BS, Leary M, Shofer FS, Grossestreuer AV, et al. Higher mean arterial pressure with or without vasoactive agents is associated with increased survival and better neurological outcomes in comatose survivors of cardiac arrest. Intensive Care Med 2013;39:1981-8.

59. Janiczek JA, Winger DG, Coppler P, Sabedra AR, Murray H, Pinsky MR, et al. Hemodynamic resuscitation characteristics associated with improved survival and shock resolution after cardiac arrest. Shock 2016;45:613-9.

60. McDonald CI, Fraser JF, Coombes JS, Fung YL. Oxidative stress during extracorporeal circulation. Eur J Cardiothorac Surg 2014;46:937-43.

61. Thangappan K, Cavarocchi NC, Baram M, Thoma B, Hirose H. Systemic inflammatory response syndrome (SIRS) after extracorporeal membrane oxygenation (ECMO): incidence, risks and survivals. Heart Lung 2016;45:449-53.

62. Vereczki V, Martin E, Rosenthal RE, Hof PR, Hoffman GE, Fiskum G. Normoxic resuscitation after cardiac arrest protects against hippocampal oxidative stress, metabolic dysfunction, and neuronal death. J Cereb Blood Flow Metab 2006;26:82135.

63. Hazelton JL, Balan I, Elmer GI, Kristian T, Rosenthal RE, Krause G, et al. Hyperoxic reperfusion after global cerebral ischemia promotes inflammation and long-term hippocampal neuronal death. J Neurotrauma 2010;27:753-62.

64. Trittenwein G, Rotta AT, Gunnarsson B, Steinhorn DM. Lipid peroxidation during initiation of extracorporeal membrane oxygenation after hypoxia in endotoxemic rabbits. Perfusion 1999; 14:49-57.

65. Mach WJ, Thimmesch AR, Pierce JT, Pierce JD. Consequences of hyperoxia and the toxicity of oxygen in the lung. Nurs Res Pract 2011;2011:260482.

66. ICU-ROX Investigators and the Australian and New Zealand Intensive Care Society Clinical Trials Group; Mackle D, Bello- 
mo R, Bailey M, Beasley R, Deane A, et al. Conservative oxygen therapy during mechanical ventilation in the ICU. N Engl J Med 2020;382:989-98.

67. Itoh H, Ichiba S, Ujike Y, Douguchi T, Obata H, Inamori S, et al. Effect of the pulsatile extracorporeal membrane oxygenation on hemodynamic energy and systemic microcirculation in a piglet model of acute cardiac failure. Artif Organs 2016;40:19-26.

68. Ostadal P, Mlcek M, Gorhan H, Simundic I, Strunina S, Hrachovina M, et al. Electrocardiogram-synchronized pulsatile extracorporeal life support preserves left ventricular function and coronary flow in a porcine model of cardiogenic shock. PLoS One 2018; 13:e0196321.

69. Short BL, Walker LK, Bender KS, Traystman RJ. Impairment of cerebral autoregulation during extracorporeal membrane oxygenation in newborn lambs. Pediatr Res 1993;33:289-94.

70. Wang S, Izer JM, Clark JB, Patel S, Pauliks L, Kunselman AR, et al. In vivo hemodynamic performance evaluation of novel electrocardiogram-synchronized pulsatile and nonpulsatile extracorporeal life support systems in an adult swine model. Artif Organs 2015;39:E90-101.

71. Passmore MR, Fung YL, Simonova G, Foley SR, Diab SD, Dunster KR, et al. Evidence of altered haemostasis in an ovine model of venovenous extracorporeal membrane oxygenation support. Crit Care 2017;21:191.

72. Luo Y, Fritz C, Hammache N, Grandmougin D, Kimmoun A, Orlowski S, et al. Low versus standard-blood-flow reperfusion strategy in a pig model of refractory cardiac arrest resuscitated with Extra Corporeal Membrane Oxygenation. Resuscitation 2018;133:12-17.

73. Cashen K, Reeder R, Dalton HJ, Berg RA, Shanley TP, Newth $\mathrm{CJ}$, et al. Hyperoxia and hypocapnia during pediatric extracorporeal membrane oxygenation: associations with complications, mortality, and functional status among survivors. Pediatr Crit Care Med 2018;19:245-53.

74. Munshi L, Kiss A, Cypel M, Keshavjee S, Ferguson ND, Fan E. Oxygen thresholds and mortality during extracorporeal life support in adult patients. Crit Care Med 2017;45:1997-2005.

75. Roberts BW, Kilgannon JH, Hunter BR, Puskarich MA, Pierce $\mathrm{L}$, Donnino $\mathrm{M}$, et al. Association between early hyperoxia exposure after resuscitation from cardiac arrest and neurological disability: prospective multicenter protocol-directed cohort study. Circulation 2018;137:2114-24.

76. Cho SM, Canner J, Chiarini G, Calligy K, Caturegli G, Rycus P, et al. Modifiable risk factors and mortality from ischemic and hemorrhagic strokes in patients receiving venoarterial extracorporeal membrane oxygenation: results from the Extracorporeal Life Support Organization Registry. Crit Care Med 2020;48: e897-905.

77. Modine T, Azzaoui R, Ouk T, Fayad G, Lacroix D, Warembourg $\mathrm{H}$, et al. Changes in cerebral vascular reactivity occur early during cardiopulmonary bypass in the rat. Ann Thorac Surg 2006;82:672-8.

78. O'Neil MP, Fleming JC, Badhwar A, Guo LR. Pulsatile versus nonpulsatile flow during cardiopulmonary bypass: microcirculatory and systemic effects. Ann Thorac Surg 2012;94:2046-53.

79. Salameh A, Kühne L, Grassl M, Gerdom M, von Salisch S, Vollroth $\mathrm{M}$, et al. Protective effects of pulsatile flow during cardiopulmonary bypass. Ann Thorac Surg 2015;99:192-9.

80. Ostadal P, Mlcek M, Kruger A, Hala P, Lacko S, Mates M, et al. Increasing venoarterial extracorporeal membrane oxygenation flow negatively affects left ventricular performance in a porcine model of cardiogenic shock. J Transl Med 2015;13:266.

81. Veraar CM, Rinösl H, Kühn K, Skhirtladze-Dworschak K, Felli A, Mouhieddine $M$, et al. Non-pulsatile blood flow is associated with enhanced cerebrovascular carbon dioxide reactivity and an attenuated relationship between cerebral blood flow and regional brain oxygenation. Crit Care 2019;23:426.

82. Groner W, Winkelman JW, Harris AG, Ince C, Bouma GJ, Messmer K, et al. Orthogonal polarization spectral imaging: a new method for study of the microcirculation. Nat Med 1999; 5:1209-12.

83. Mehra MR, Uriel N, Naka Y, Cleveland JC Jr, Yuzefpolskaya M, Salerno CT, et al. A fully magnetically levitated left ventricular assist device: final report. N Engl J Med 2019;380:1618-27.

84. Risnes I, Wagner K, Nome T, Sundet K, Jensen J, Hynås IA, et al. Cerebral outcome in adult patients treated with extracorporeal membrane oxygenation. Ann Thorac Surg 2006;81:14016.

85. Cho SM, Canner J, Caturegli G, Choi CW, Etchill E, Giuliano K, et al. Risk factors of ischemic and hemorrhagic strokes during venovenous extracorporeal membrane oxygenation: analysis of data from the Extracorporeal Life Support Organization Registry. Crit Care Med 2021;49:91-101.

86. Cho SM, Farrokh S, Whitman G, Bleck TP, Geocadin RG. Neurocritical care for extracorporeal membrane oxygenation patients. Crit Care Med 2019;47:1773-81.

87. Cho SM, Geocadin RG, Caturegli G, Chan V, White B, Dodd-O $\mathrm{J}$, et al. Understanding characteristics of acute brain injury in adult extracorporeal membrane oxygenation: an autopsy study. Crit Care Med 2020;48:e532-6.

88. Wilcox C, Etchill E, Giuliano K, Mayasi Y, Gusdon AM, Choi $\mathrm{CW}$, et al. Acute brain injury in postcardiotomy shock treated with venoarterial extracorporeal membrane oxygenation. J Cardiothorac Vasc Anesth 2021;35:1989-96. 
89. Cho SM, Ziai W, Geocadin R, Choi CW, Whitman G. Arterial-sided oxygenator clot and transcranial doppler ultrasound emboli in venoarterial extracorporeal membrane oxygenation. Ann Thorac Surg 2019; 107:326-7.

90. Cho SM, Deshpande A, Pasupuleti V, Hernandez AV, Uchino K. Radiographic and clinical brain infarcts in cardiac and diagnostic procedures: a systematic review and meta-analysis. Stroke 2017;48:2753-9.

91. Zwischenberger JB, Nguyen TT, Upp JR, Bush PE, Cox CS Jr, Delosh T, et al. Complications of neonatal extracorporeal membrane oxygenation: collective experience from the Extracorporeal Life Support Organization. J Thorac Cardiovasc Surg 1994;107:838-48.

92. Horton AM, Butt W. Pump-induced haemolysis: is the constrained vortex pump better or worse than the roller pump? Perfusion 1992;7:103-8.

93. Hwang J, Caturegli G, White B, Chen L, Cho SM. Cerebral microbleeds and intracranial hemorrhages in adult patients on extracorporeal membrane oxygenation-autopsy study. Crit Care Explor 2021;3:e0358.

94. Ong BA, Geocadin R, Choi CW, Whitman G, Cho SM. Brain magnetic resonance imaging in adult survivors of extracorporeal membrane oxygenation. Perfusion 2020 Nov 12 [Epub]. https://doi.org/10.1177/0267659120968026.

95. Liebeskind DS, Sanossian N, Sapo ML, Saver JL. Cerebral microbleeds after use of extracorporeal membrane oxygenation in children. J Neuroimaging 2013;23:75-8.

96. Le Guennec L, Bertrand A, Laurent C, Roze H, Chastre J, Combes A, et al. Diffuse cerebral microbleeds after extracorporeal membrane oxygenation support. Am J Respir Crit Care Med 2015;191:594-6.

97. Greenberg SM, Vernooij MW, Cordonnier C, Viswanathan A, Al-Shahi Salman R, Warach S, et al. Cerebral microbleeds: a guide to detection and interpretation. Lancet Neurol 2009; 8:165-74.

98. Frenckner B, Broman M, Broomé M. Position of draining venous cannula in extracorporeal membrane oxygenation for respiratory and respiratory/circulatory support in adult patients. Crit Care 2018;22:163.

99. Kitamura M, Shibuya M, Kurihara H, Akimoto T, Endo M, Koyanagi H. Effective cross-circulation technique of venoarterial bypass for differential hypoxia condition. Artif Organs 1997;21:786-8.

100. Contento C, Battisti A, Agrò B, De Marco M, Iaiza A, Pietraforte $\mathrm{L}$, et al. A novel veno-arteriovenous extracorporeal membrane oxygenation with double pump for the treatment of Harlequin syndrome. Perfusion 2020;35(1_suppl):65-72.
101. Rupprecht L, Lunz D, Philipp A, Lubnow M, Schmid C. Pitfalls in percutaneous ECMO cannulation. Heart Lung Vessel 2015;7:320-6.

102. Lorusso R, Taccone FS, Belliato M, Delnoij T, Zanatta P, Cvetkovic $\mathrm{M}$, et al. Brain monitoring in adult and pediatric ECMO patients: the importance of early and late assessments. Minerva Anestesiol 2017;83:1061-74.

103. Cho SM, Ziai W, Mayasi Y, Gusdon AM, Creed J, Sharrock M, et al. Noninvasive neurological monitoring in extracorporeal membrane oxygenation. ASAIO J 2020;66:388-93.

104. Cho SM, Ritzl EK. Neurological prognostication using electroencephalogram in adult veno-arterial extracorporeal membrane oxygenation: limitations and recommendations. Neurocrit Care 2020;33:652-4.

105. Khan I, Rehan M, Parikh G, Zammit C, Badjatia N, Herr D, et al. Regional cerebral oximetry as an indicator of acute brain injury in adults undergoing veno-arterial extracorporeal membrane oxygenation: a prospective pilot study. Front Neurol 2018;9:993.

106. Marinoni M, Migliaccio ML, Trapani S, Bonizzoli M, Gucci L, Cianchi G, et al. Cerebral microemboli detected by transcranial doppler in patients treated with extracorporeal membrane oxygenation. Acta Anaesthesiol Scand 2016;60:934-44.

107. Hunt MF, Clark KT, Whitman G, Choi CW, Geocadin RG, Cho SM, et al. The use of cerebral NIRS monitoring to identify acute brain injury in patients with VA-ECMO. J Intensive Care Med 2020 Oct 15 [Epub]. https://doi.org/10.1177/088 5066620966962.

108. Callaway CW, Donnino MW, Fink EL, Geocadin RG, Golan E, Kern KB, et al. Part 8: post-cardiac arrest care: 2015 American Heart Association Guidelines update for cardiopulmonary resuscitation and emergency cardiovascular care. Circulation 2015;132(18 Suppl 2):S465-82.

109. Cho SM, Choi CW, Whitman G, Suarez JI, Martinez NC, Geocadin RG, et al. Neurophysiological findings and brain injury pattern in patients on ECMO. Clin EEG Neurosci 2019 Dec 11 [Epub]. https://doi.org/10.1177/1550059419892757.

110. Magalhaes E, Reuter J, Wanono R, Bouadma L, Jaquet P, Tanaka S, et al. Early EEG for prognostication under venoarterial extracorporeal membrane oxygenation. Neurocrit Care 2020; 33:688-94.

111. Ryu JA, Chung CR, Cho YH, Sung K, Suh GY, Park TK, et al. The association of findings on brain computed tomography with neurologic outcomes following extracorporeal cardiopulmonary resuscitation. Crit Care 2017;21:15.

112. Floerchinger B, Philipp A, Foltan M, Keyser A, Camboni D, Lubnow $\mathrm{M}$, et al. Neuron-specific enolase serum levels predict 
severe neuronal injury after extracorporeal life support in resuscitation. Eur J Cardiothorac Surg 2014;45:496-501.

113. Ferraro S, Braga F, Luksch R, Terenziani M, Caruso S, Panteghini M. Measurement of serum neuron-specific enolase in neuroblastoma: is there a clinical role? Clin Chem 2020;66:66775.

114. Nguyen DN, Huyghens L, Wellens F, Schiettecatte J, Smitz J, Vincent JL. Serum S100B protein could help to detect cerebral complications associated with extracorporeal membrane oxygenation (ECMO). Neurocrit Care 2014;20:367-74.

115. Gazzolo D, Masetti P, Meli M, Grutzfeld D, Michetti F. Elevated S100B protein as an early indicator of intracranial haemorrhage in infants subjected to extracorporeal membrane oxygenation. Acta Paediatr 2002;91:218-21.

116. Bembea MM, Savage W, Strouse JJ, Schwartz JM, Graham E, Thompson CB, et al. Glial fibrillary acidic protein as a brain injury biomarker in children undergoing extracorporeal mem- brane oxygenation. Pediatr Crit Care Med 2011;12:572-9.

117. Mattsson N, Zetterberg H, Nielsen N, Blennow K, Dankiewicz J, Friberg H, et al. Serum tau and neurological outcome in cardiac arrest. Ann Neurol 2017;82:665-75.

118. Kirschen MP, Yehya N, Graham K, Kilbaugh T, Berg RA, Topjian $\mathrm{A}$, et al. Circulating neurofilament light chain is associated with survival after pediatric cardiac arrest. Pediatr Crit Care Med 2020;21:656-61.

119. Moseby-Knappe M, Mattsson N, Nielsen N, Zetterberg H, Blennow K, Dankiewicz J, et al. Serum neurofilament light chain for prognosis of outcome after cardiac arrest. JAMA Neurol 2019;76:64-71.

120. Gul SS, Huesgen KW, Wang KK, Mark K, Tyndall JA. Prognostic utility of neuroinjury biomarkers in post out-of-hospital cardiac arrest (OHCA) patient management. Med Hypotheses 2017;105:34-47. 